Article

\title{
Load Estimation of Offshore Wind Turbines
}

\author{
Sang Lee 1,*(D), Matthew Churchfield ${ }^{2}$, Frederick Driscoll ${ }^{2}$, Senu Sirnivas ${ }^{2}$, Jason Jonkman ${ }^{2}$, \\ Patrick Moriarty ${ }^{2}$, Bjórn Skaare ${ }^{3}$, Finn Gunnar Nielsen ${ }^{4}$ and Erik Byklum ${ }^{3}$ \\ 1 Department of Mechanical Engineering, University of New Mexico, Albuquerque, NM 87131, USA \\ 2 National Renewable Energy Laboratory, Golden, CO 80401, USA; matt.churchfield@nrel.gov (M.C.); \\ frederick.driscoll@nrel.gov (F.D.); senu.sirnivas@nrel.gov (S.S.); jason.jonkman@nrel.gov (J.J.); \\ patrick.moriarty@nrel.gov (P.M.) \\ 3 Statoil, 4035 Stavanger, Norway; bjoska@statoil.com (B.S.); ebk@statoil.com (E.B.) \\ 4 Geophysical Institute, University of Bergen, 7803 Bergen, Norway; Finn.Nielsen@uib.no \\ * Correspondence: sanglee@unm.edu; Tel.: +1-505-277-1162
}

Received: 6 May 2018; Accepted: 16 July 2018; Published: 20 July 2018

\begin{abstract}
The influence of 3 MW Hywind-II wind turbine wakes from an upstream offshore floating wind turbine on a downstream turbine with a separation distance of seven rotor diameters was studied for a site in the Gulf of Maine. The turbines and the platforms were subjected to atmospheric boundary layer flows. Various sensitivity studies on fatigue loads with respect to the positions of the downstream turbine were performed and validated with a large-eddy simulation tool. In particular, the effect of various lateral positions of the downstream turbine relative to the upstream turbine were considered using time-series turbine wake data generated from the large-eddy simulation tool which served as an input to an aero-elastic wind turbine model to assess the loads. The load response from the rotor, tower, and the floating platform for the downstream turbine were sensitive to the lateral offset positions where turbines that were partially exposed to upstream turbine wakes yielded significant increases in the cyclic load range. For the given set of lateral positions for the downstream turbine, the largest damage equivalent load occurred when the turbine was one rotor diameter to the left of the centerline, when looking upstream, which is the position of the turbine fully exposed to upstream turbine wake. On the other hand, the fatigue load on the downstream turbine placed on the right side of the position fully exposed to the upstream turbine wake, yielded lower stress due to the non-symmetric shape of the turbine wake. The configuration associated with the largest damage equivalent loads was further investigated in a large-eddy simulation, modeling both the upstream and downstream turbines. It was found that the energy spectra at the blade rotational frequency were a magnitude order higher for the downstream turbine, especially for surge, heave, pitch, and yaw motion of the platform. The increase of the damage equivalent load for the flapwise blade root moment was $45 \%$ compared to the upstream turbine, which can potentially reduce the turbine service life time.
\end{abstract}

Keywords: atmospheric boundary layer; wind turbines; damage equivalent load

\section{Introduction}

The present study investigates the influence of turbine wakes originating from an upstream offshore floating wind turbine (OFWT) on a downstream turbine for a site in the Gulf of Maine. The rated power of the wind turbine is $3 \mathrm{MW}$, which is supported by a Hywind-II [1] floating spar platform anchored with chain catenary moorings and drag embedment anchors at $140 \mathrm{~m}$ water depth (further details on the wind turbine are proprietary). The interaction between atmospheric boundary layer $(\mathrm{ABL})$ and wind turbines and their wake influence on the downwind turbines is difficult to model using analytical means. Accurate predictive methods are crucial for turbine siting, optimizing 
the power output, and reducing fatigue loads, because these are important drivers to determining power performance and levelized cost of energy (LCOE). As accuracy is critical in assessing merits of the wind farm layout, further studies are needed to investigate the wind turbine performance deficits throughout the wind farm.

Because analytical tools to calculate wake deficits in large wind farms are based on empirical formulas that do not catch the true essence of the wake field, a wind turbine structural analysis program (FAST [2]) is coupled to a computational fluid dynamics (CFD) program to compute the turbulence intensity of a floating offshore wind turbine farm. This coupled fluid-structure interaction program, known as "Simulator fOr Wind Farm Applications" (SOWFA) [3], provides more insight into the performance of the proposed Hywind-II spar design that is subjected to realistic atmospheric turbulence, wave excitations, and turbine wake interactions. Floating offshore wind turbines introduce new complexities that have not been studied in depth in the past. The platform itself is not fixed but translates and rotates because of its compliant mooring system. The results will provide the knowledge of how spacing of seven rotor diameters (7D) between wind turbines affects power production, fatigue loads, and platform motions. The actuator disk (ADM) [4] and the actuator line (ALM) [5] methods have been the key to large-eddy simulation (LES) of wind farms. The ADM and ALM have been compared in Stevens et al. [6], and the results yielded good agreement with the experimental data beyond three rotor diameters downstream of the turbine. They also found that the inclusion of the turbine nacelle and the tower in the simulation led to improved prediction in the near wake regions. A fully coupled fluid-structure interaction study by Calderer et al. [7] was performed using LES of two-phase flow, which consisted of air and water to simulate a floating wind turbine coupled with realistic ocean wind and waves. In this study, an immerse-boundary method was employed to model the floating structure, while the ALM was used to represent the blade motion. The proposed computational method was able to capture the turbine response in the six degrees-of-freedom of the platform motions, and the resulting turbine dynamics from the atmospheric flow. The ALM was also used in a horizontal axis tidal stream turbine [8], which performed well in reproducing the mean flow and the turbulence statistics downstream of the turbine. The predicted flow field exhibited the evolution of the helical vortices transitioning to a fully mixed turbulent flow further downstream. Recently, there have been efforts to further improve the ALM by better capturing the tip and the root vortices via a 2D Gaussian kernel, as reported by Martinez-Tossas et al. [9]. The improved method enabled the ALM to resolve flows around the blade tip. However, further improvement in the methodology and validation are still needed. Historically, SOWFA has been applied in the study of turbine wake interactions on land-based wind farms [10]. The present work builds on the previous studies to provide time-dependent data from LES with a fully coupled aero-elastic tool.

Previous studies of OFWT are summarized in Jonkman and Matha [11], in which three primary floating wind turbine concepts were investigated to study the dynamic coupling between the turbine and the floating platform. All of the floating turbines exhibited increased loads compared to the land-based system and thus required further structural strengthening as the platform motion induced ultimate and fatigue loads for all turbine components. Another study of OFWT, by Christiansen et al. [12], was performed to investigate a control strategy to damp the structural oscillations while maximizing power generation. These previous studies were conducted using the aero-elastic simulation tool, FAST, with turbulent inflows generated from a reduced-order turbulence model, TurbSim [13], and the hydro-dynamic forces that were computed from coefficients derived by WaveAnalysisMIT (WAMIT) [14]. Several mid-fidelity wind turbine wake models have been employed using the free vortex method (FVM) [15] to improve the calculations of the wind-wave induced platform motion coupled with the induction produced by the turbine rotor. Another FVM was used [16] to enhance the predictive capability of modeling the OFWT from the traditional blade-element momentum theory. It was shown that a turbulent wake state (TWS) is yielded if the floating turbine pitches upwind. The convection of the tip vortex was the critical factor in characterizing the behavior of the rotor in the TWS. 
The present study employs a high-fidelity tool based on a large-eddy simulation approach in which a coupled fluid-structure interaction tool has been applied to a study of floating offshore wind turbines. The scope of the study includes the following steps: (1) extract a time series of planar wind data at 7D downstream from the turbine to use as an input to FAST (one-way coupling from SOWFA to FAST); (2) conduct six runs of various turbine positions using FAST, with the time-series planar data input to better understand the load response for downstream turbines that are fully or partially exposed to upstream turbine wakes caused by various lateral offset positions; (3) select the worst case with the highest fatigue loading scenario from the above FAST runs and replicate the same configuration using SOWFA with both upstream and downstream turbines separated by 7D; and (4) lastly, compare results from the one-way and two-way coupled simulations.

\section{Methodology}

The computational framework consists of several components. LES is used to simulate the atmospheric boundary layer that solves the incompressible formulation of the Navier-Stokes equation with the addition of potential temperature transport equations. The buoyancy force is described by the Boussinesq approximation to eliminate the need to recast the governing equations into a compressible form, which requires extensive computer resources. To account for planetary rotation, the Coriolis force is included in the momentum equation. The turbine blades were modeled using the ALM coupled with FAST, which uses modal and multi-body dynamics. The deformable blades and the tower assume small deflections. The LES framework and solver are detailed in Reference [10]. Several publications have been released using the computational tool in the present study $[10,17,18]$.

The turbulent inflow boundary condition was generated via precursor simulation as shown in Figure 1. In the present study, the lateral length of the domain was $3 \mathrm{~km}$ while the vertical height was $1 \mathrm{~km}$, to allow a full development of a wide spectrum of turbulent structures (Figure 1a). The mesh size was fixed with an $8 \mathrm{~m}$ uniform grid. As shown in Figure 1b, the west boundary is saved at every time step into time-series data. The driver for the wind is based on the pressure gradient to obtain a mean wind speed of $9 \mathrm{~m} / \mathrm{s}$ at the turbine hub-height $(\mathrm{z}=69 \mathrm{~m}$ relative to the mean sea level). The turbulent intensity was adjusted to $3.7 \%$ based on the freestream velocity. Two-dimensional cuts of instantaneous streamwise velocity contours are shown in Figure 2, in which the boundary layer height was determined to be approximately $400 \mathrm{~m}$. The streamwise velocity profile shown in Figure $3 \mathrm{a}$ is the mean inflow condition in which the energy spectrum for the velocity field at the inflow taken at the hub-height resolved the inertial range (Figure 3b).

*Top BC: slip BC

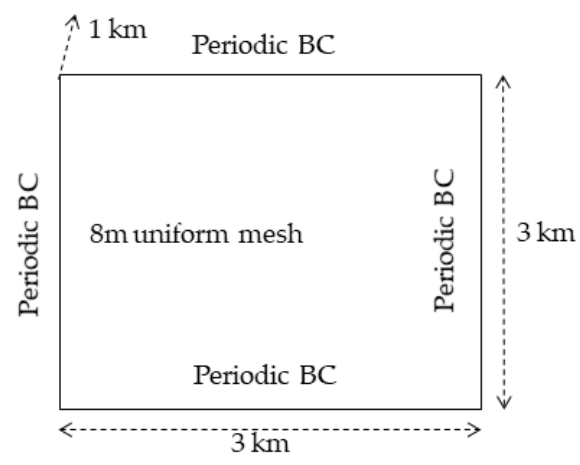

(a)

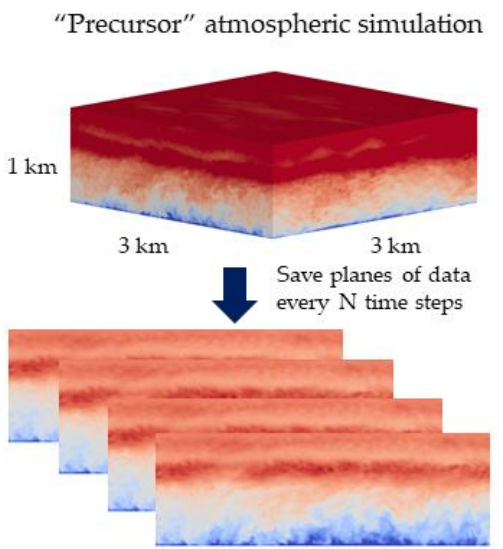

(b)

Figure 1. (a) horizontal projection of computational domain, (b) precursor simulations to generate turbulent inflow boundary data. BC: boundary condition. 

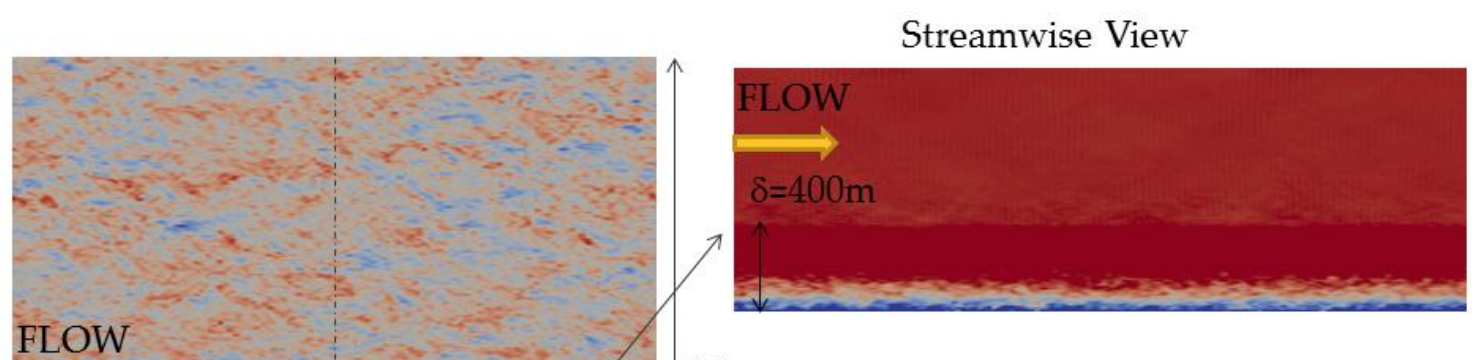

$3 \mathrm{~km}$
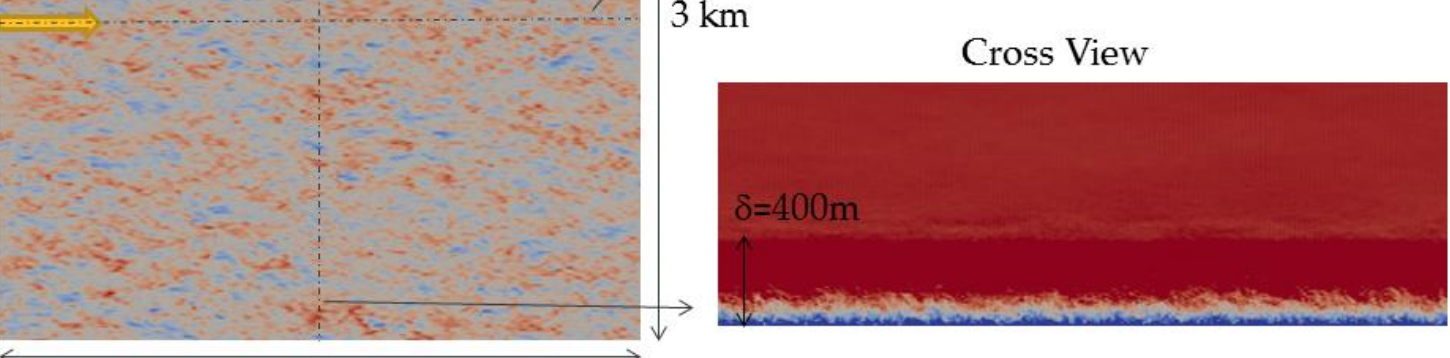

$3 \mathrm{~km}$

Figure 2. Instantaneous streamwise velocity contours.

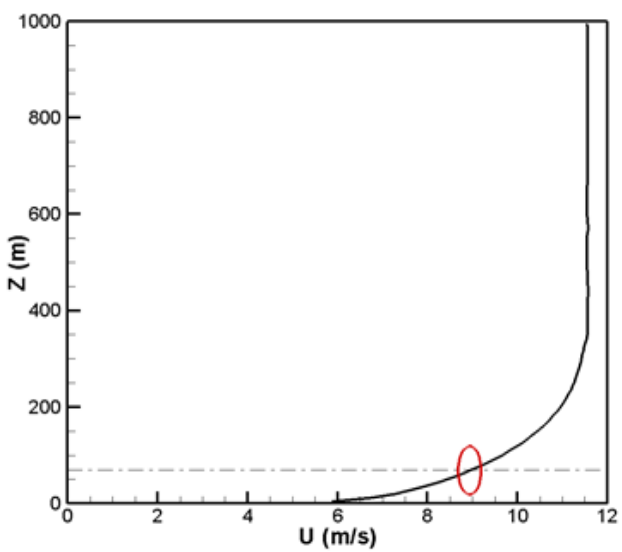

(a)

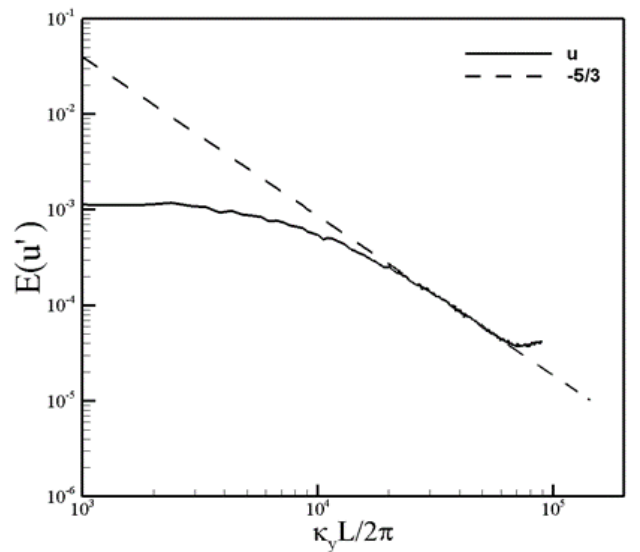

(b)

Figure 3. (a) Streamwise velocity profile with turbine rotor denoted by red circle and, (b) streamwise velocity spectra.

\section{Environmental Condition and Sites}

The external environmental loading imposed on the spar consisted of the wind and associated wave conditions, without a current, listed in Table 1.

Table 1. Wind and wave conditions.

\begin{tabular}{ccc}
\hline Hub-height Wind Speed & Significant Wave Height & Spectral Peak Wave Period \\
\hline $9.0 \mathrm{~m} / \mathrm{s}$ & $4.2 \mathrm{~m}$ & $10.57 \mathrm{~s}$ \\
\hline
\end{tabular}

\section{Results}

The schematic of the computational domain with the $3 \mathrm{MW}$ wind turbine included is shown in Figure 4. Two additional nestings of grid refinement were performed, which yielded a 2-m resolution to better capture the blade vortices. To identify the most extreme loading case for the downstream turbine (WT2), time-series data at 7D downstream from the upstream turbine (WT1), as shown in 
Figure 4, were collected. The time-series data were then fed into FAST for load analysis as a one-way coupling approach. The dimension of the data plane is $2 \mathrm{D}$ in height with a 5D lateral spacing to sufficiently accommodate various lateral positions of WT2. The follow-on approach was to select a turbine lateral position that results in the highest fatigue load based on damage equivalent load (DEL). DEL quantifies fatigue for a constant amplitude cyclic load that yields the equivalent damage from an actual repetitive loading condition [19]. The selected lateral position was then simulated with SOWFA with both WT1 and WT2 as a two-way coupling process approach. The six lateral positions for WT2 were $-1 \mathrm{D},-0.5 \mathrm{D}, 0,0.5 \mathrm{D}, 1 \mathrm{D}$, and 1.5D. The lateral position schematic is shown in Figure 5 (view looking upstream from behind WT2). The neutral position, 0 , corresponded to the centerline position, which was directly downstream of WT1, while the other positions were offsets from the centerline. The 1.5D lateral position shows that WT2 is in a region similar to the WT1 exposed to the freestream flow.

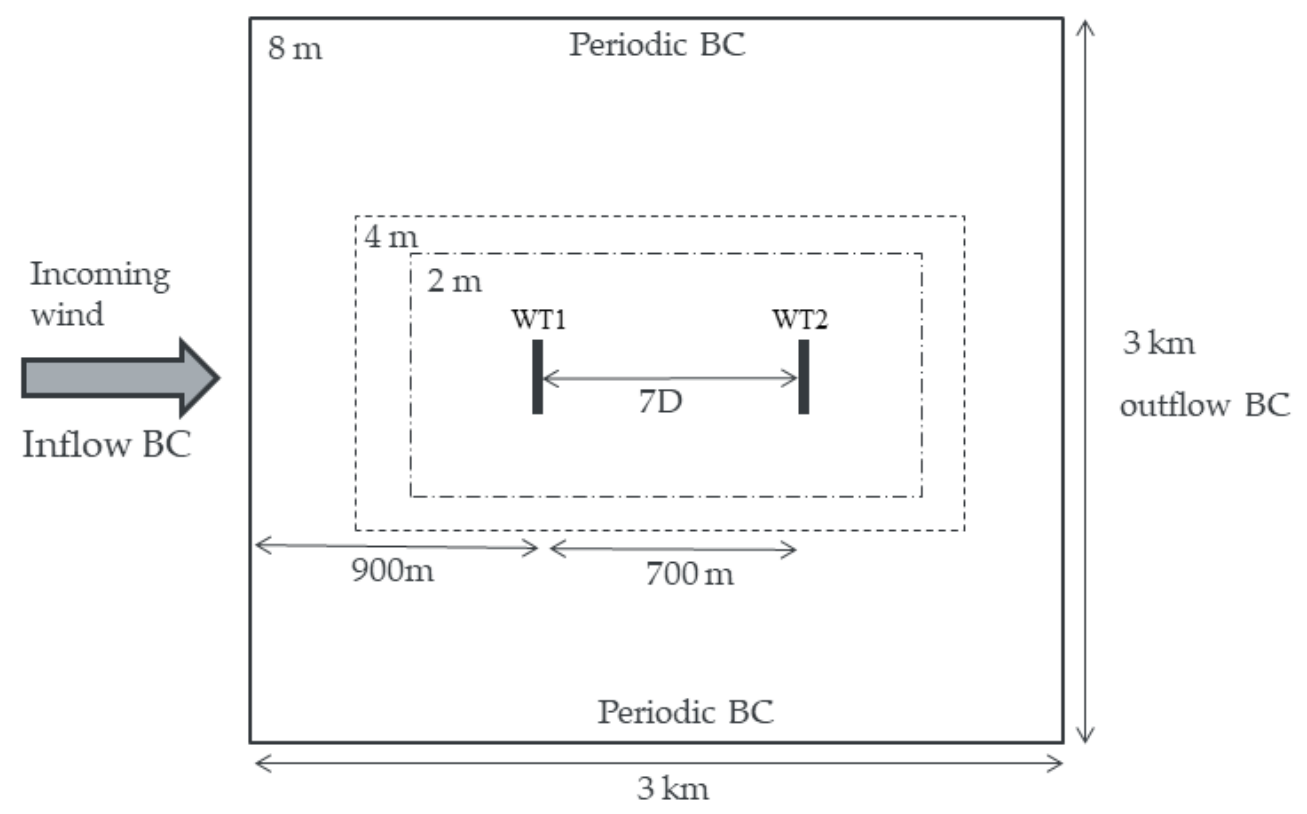

Figure 4. Horizontal projection of computational domain for planar data extraction.

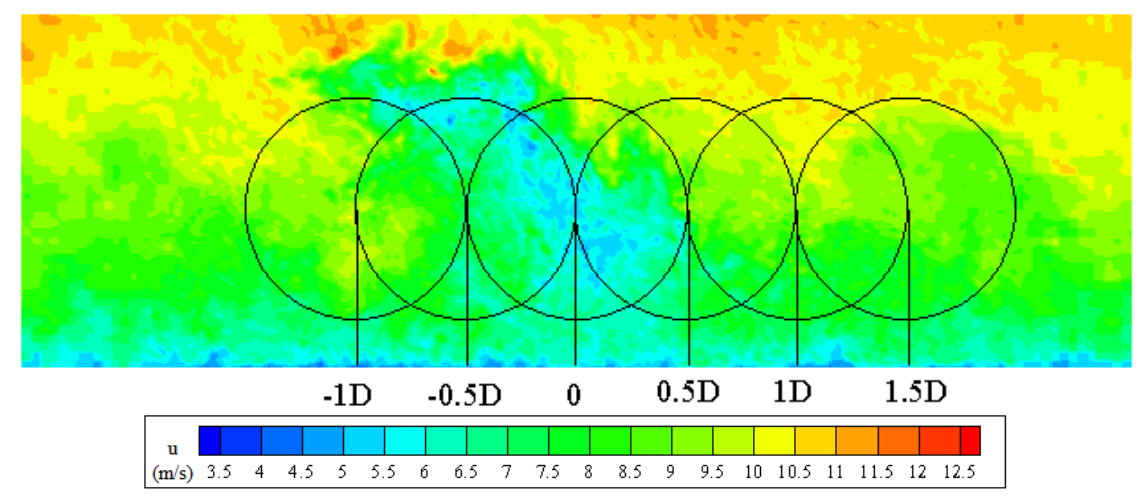

Figure 5. Various turbine positions $-1 \mathrm{D},-0.5 \mathrm{D}, 0,0.5 \mathrm{D}, 1.0 \mathrm{D}$, and $1.5 \mathrm{D}$, and the instantaneous streamwise velocity contour shown in the flow direction.

\subsection{Turbine and Platform Response}

The turbine generator output and the flapwise blade root moment are shown in Figure 6 with a $100 \mathrm{~s}$ window for visual clarity. The cases of 0 and lateral offset of $-0.5 \mathrm{D}$ exhibited significant 
reductions in the generator power output and the flapwise blade root moment due to strong wake deficits that were skewed to the left (Figure 5). Conversely, turbines positioned at 1D and 1.5D yielded loads and power outputs that were comparable to WT1 (not shown in the plot), as the wake deficit structures were not generally active in this region. The corresponding platform motions supported by the spar are illustrated in Figure 7. The surge and pitch motions of the turbine in the wake showed that the mean components were less compared to the region without wakes, consistent with smaller thrust force and lower power production. In the cases with a strong wake deficit, notably $-0.5 \mathrm{D}$ and 0 , the motion trajectories were suppressed compared to other offset positions where wake deficit impacts were smaller. For the 1.5D position, fluctuations in the motion signals, especially for sway and roll, were significantly reduced as this lateral position was outside of the wake deficit region.

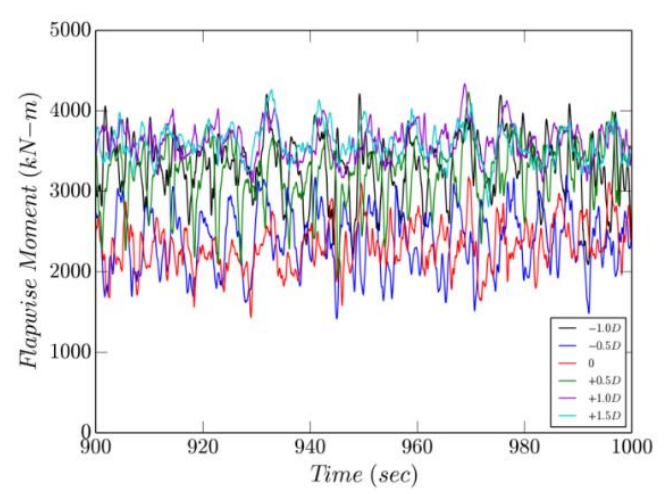

(a)

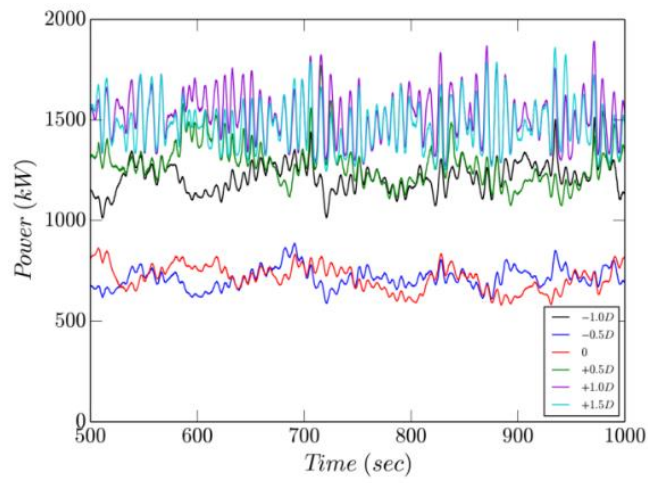

(b)

Figure 6. (a) WT2 power and (b) flapwise blade root moment for various lateral positions.

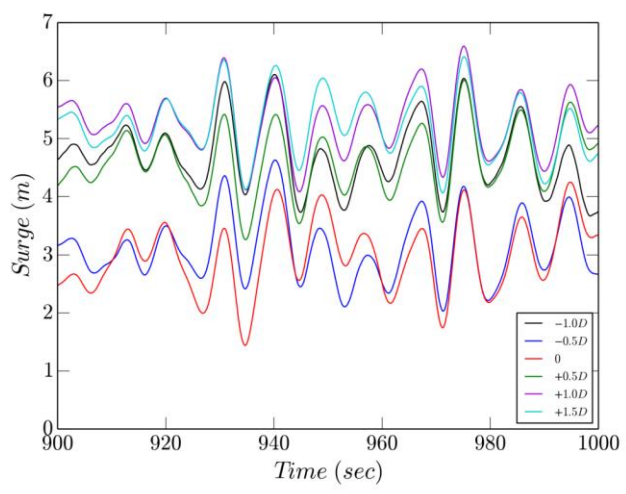

(a)

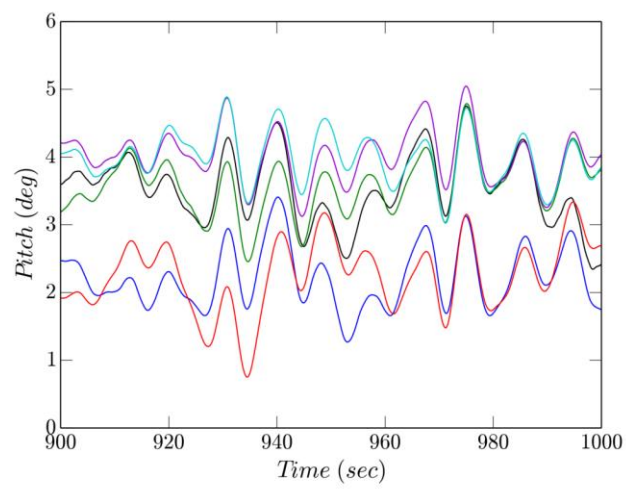

(c)

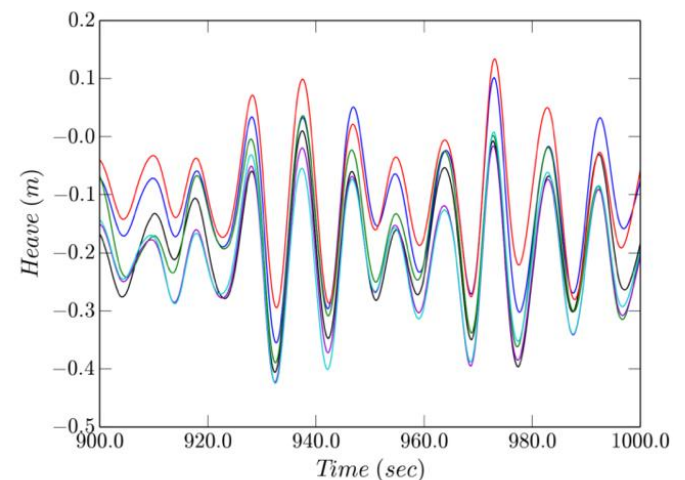

(b)

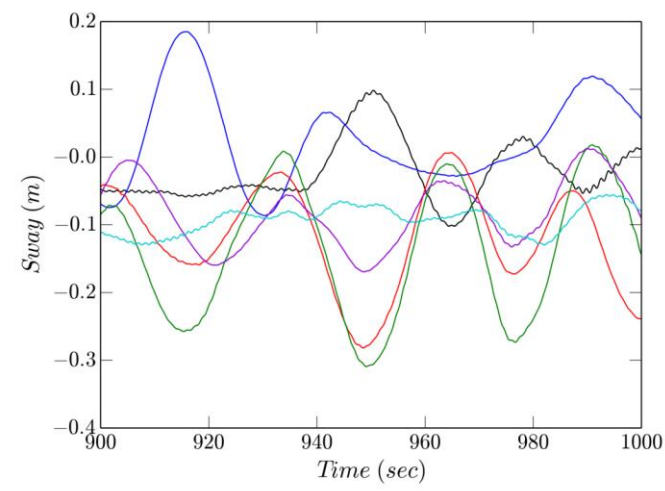

(d)

Figure 7. Cont. 


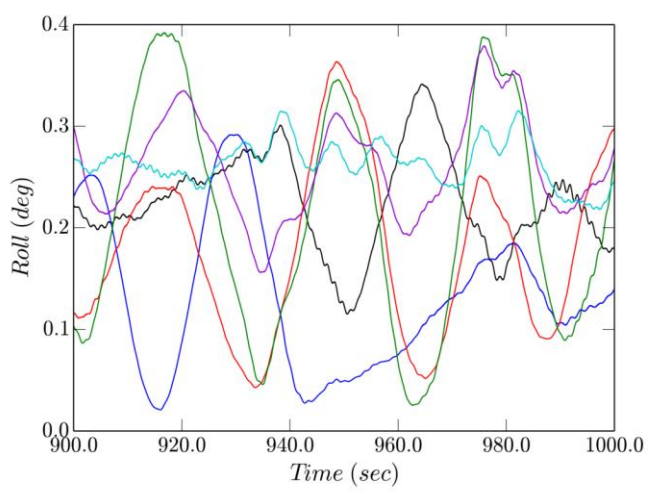

(e)

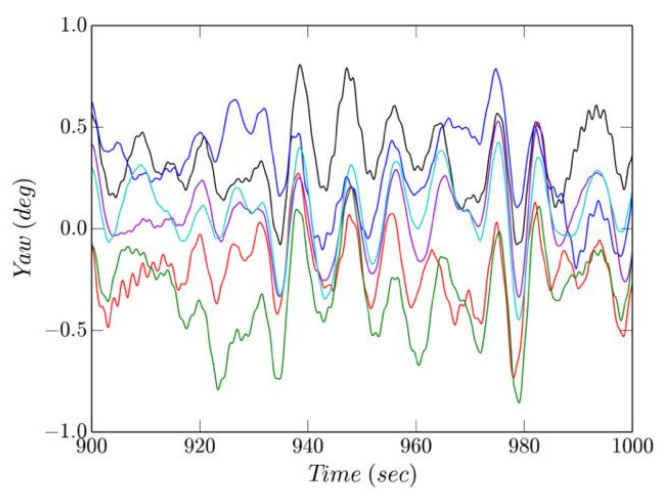

(f)

Figure 7. WT2 motions of (a) surge, (b) heave, (c) pitch, (d) sway, (e) roll, and (f) yaw for various lateral positions.

\subsection{Damage Equivalent Loads}

DEL derived from the time-series load data at the blade and the tower root were computed from cycles extracted using a rainflow cycling counting algorithm [19] as shown in Figure 8. The four measured stations (edgewise and flapwise blade root moments and, for the tower, side-to-side and fore-aft directions) were selected based on where the largest loads occurred during operation. The Wohler exponent for the blade was 10, which is a typical exponent that represents blade composite materials. The exponent used for the tower was 3, which assumed the tower to be made of steel. The Goodman method [20] was used for the correction of the cyclic midpoint in which the ultimate loads were derived from maximum values from loads on the blade and towers. The DEL for WT1 from SOWFA is included in the blade root moments, which compares well with results of the 1.5D case. As shown in Figure 8, DEL is greatest for the $-1.0 \mathrm{D}$ lateral position case for the blade root moments and the tower base fore-aft moments, which was attributed to the blade tip partially being exposed to the upstream wake. In the case of the flapwise blade root moment, a $45 \%$ increase in the DEL was observed for WT2 compared to that of WT1.

As the rotor passes through the wake deficit region, shown in Figure 9, additional cyclic loads were introduced to the turbine components. Note from Figure 8 that the DEL of the flapwise blade root moment in WT1 was significantly lower in comparison to WT2 positioned at $-1 \mathrm{D},-0.5 \mathrm{D}, 0$, and $+0.5 \mathrm{D}$.

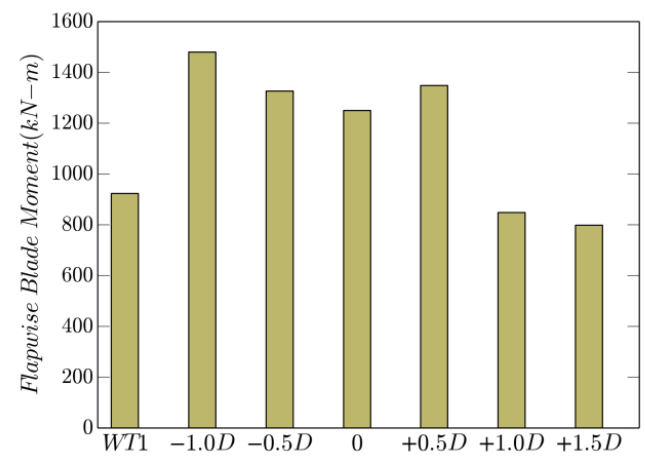

(a)

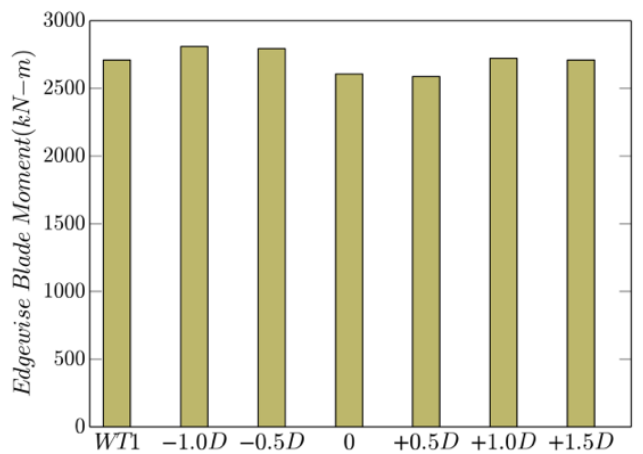

(b)

Figure 8. Cont. 


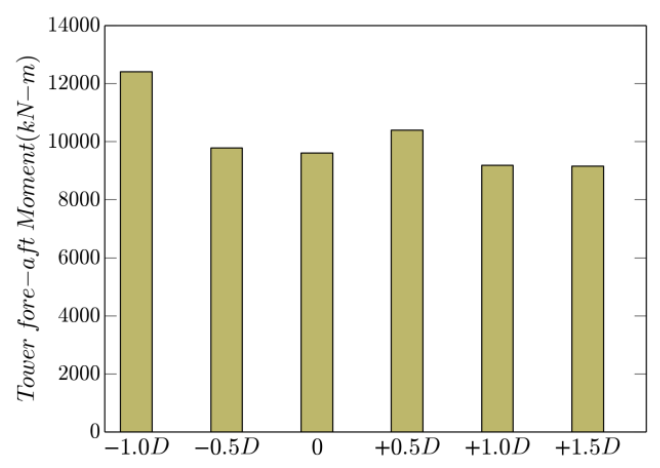

(c)

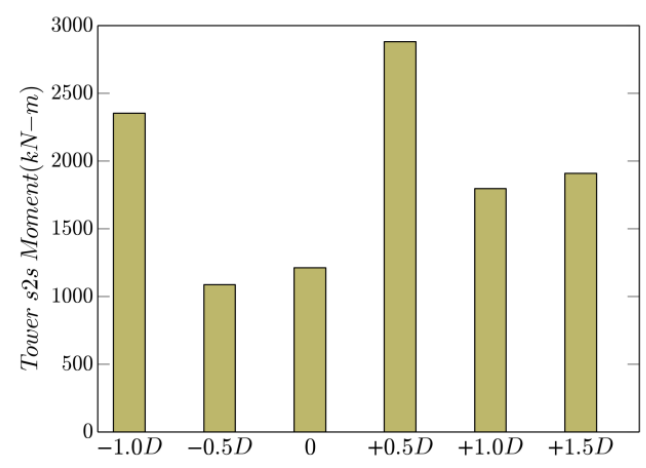

(d)

Figure 8. Damage equivalent loads for (a) flapwise blade root, (b) edgewise blade root, (c) tower fore-aft, and (d) tower side-to-side moments.

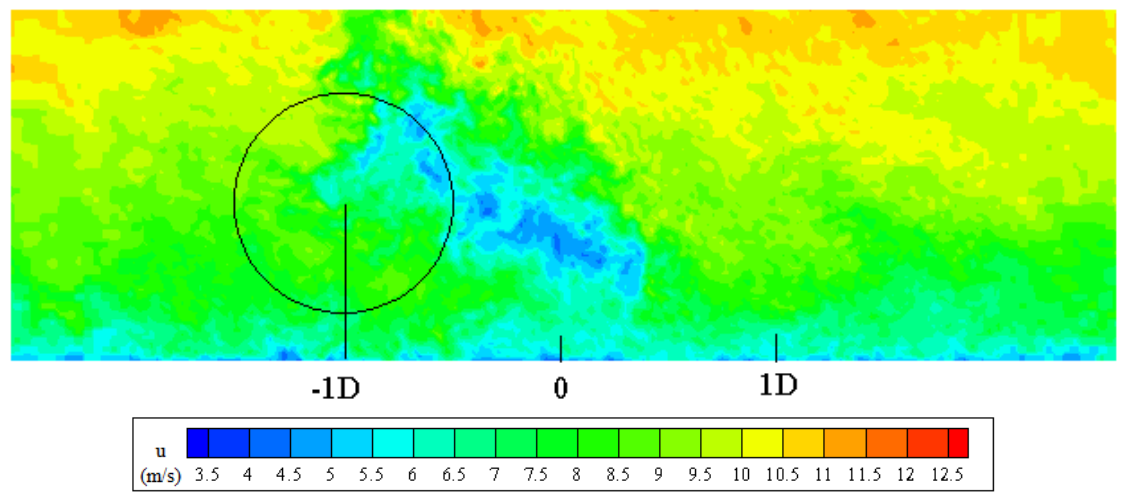

Figure 9. WT2 instantaneous streamwise velocity contours.

The wake deficit region was non-symmetric based on two speculative reasons. First, the wake rotated counter to the rotor rotation, and the wind profile had vertical shear (i.e., the winds at the top of the rotor plane were faster than at the bottom of the rotor). Hence, low-speed flow from below rotated up to the right side of the wake and high-speed flow rotated down to the left side of the wake. Second, Coriolis forces acting on the wind caused a direction change with height. This wind veer distorted the wake, making it appear tilted to one side. Thus, the right side of the wake was weaker than the left, causing lower stresses on a turbine positioned to the right of the full wake position. At 1D and 1.5D, WT2 DELs were similar to those of WT1 due to the lack of wake present. DELs for the various lateral positions were similar for the edgewise blade root moment, which was attributed to the gravity loads dominantly acting on the heavy blades.

\subsection{Large-Eddy Simulation Fully Coupled with FAST}

Investigation of the six lateral positions of WT2 revealed the overall highest DEL for the lateral position of $-1.0 \mathrm{D}$ (Figure 8). This case was selected for further studies using SOWFA with both WT1 and WT2 in which the computational fluid dynamics solver and FAST were two-way coupled. It should be noted that the wave field was synchronous for both WT1 and WT2. At 7D apart, the wave diffraction effects were considered negligible. An instantaneous streamwise velocity contour at the turbine hub-height is shown in Figure 10, in which similar partial impingement of the upstream wake can be observed where the edge of the upstream wake was impinging on the WT2 rotor. The WT2 blade traveled through both high and low velocity regions, which contributed to the overall increase in fatigue (due to greater cyclic load range) on the turbine components. In addition, the merging of the 
two wakes, shown in Figure 10, could potentially introduce added fatigue on a third turbine farther downstream within a wind farm.

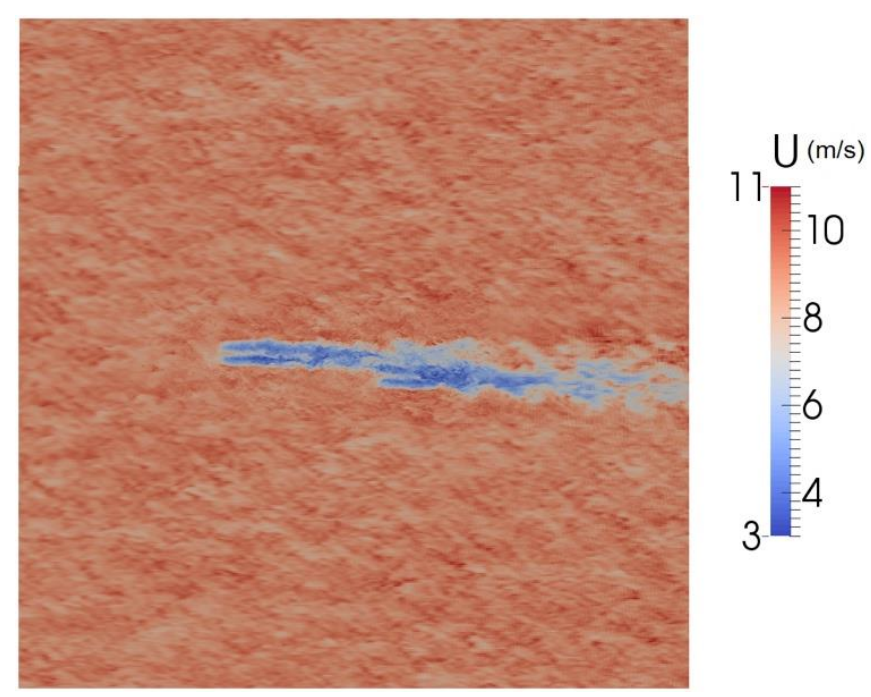

Figure 10. Instantaneous streamwise velocity (U) contour.

The power output and the flapwise blade root moment from the turbine, and the floating platform motions, are shown in Figures 11 and 12 (windowed from $1000 \mathrm{~s}$ to $1100 \mathrm{~s}$ for clarity), respectively. Because of partial impingement of the upstream wake on WT2, reduction in power generation was observed. Although the fluctuations were smaller in power generation for WT2 compared to those of WT1, the platform translational and rotational motions were affected. The upstream wake that was partially impinging on the tip of the WT2 rotor exerts additional disturbance, which leads to larger motions of the turbine platform, especially in the case of platform yaw response. The DELs for the blade root and the tower base moments computed from the SOWFA result yielded reasonable agreement with the previous study using FAST with the same inflow with upstream wakes generated from SOWFA. The maximum difference observed was 10\%, as shown in Figure 13.

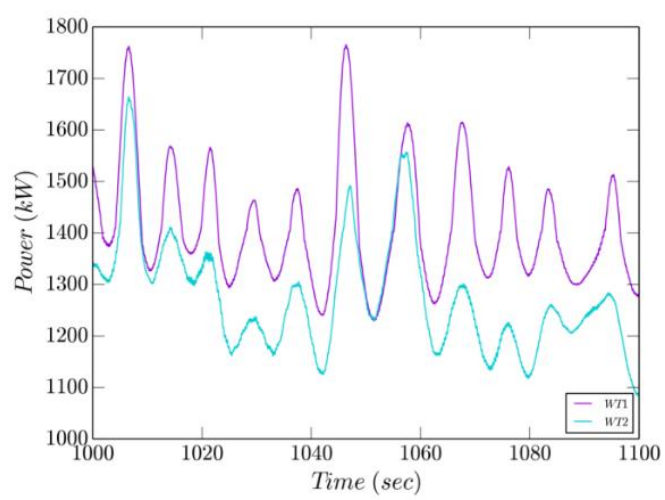

(a)

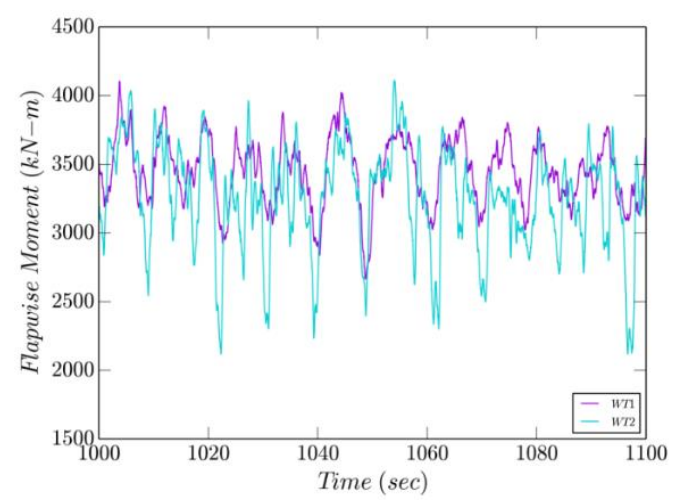

(b)

Figure 11. (a) Power and (b) flapwise blade root moment from SOWFA (Simulator fOr Wind Farm Applications) in which WT2 is offset by $-1 \mathrm{D}$. 


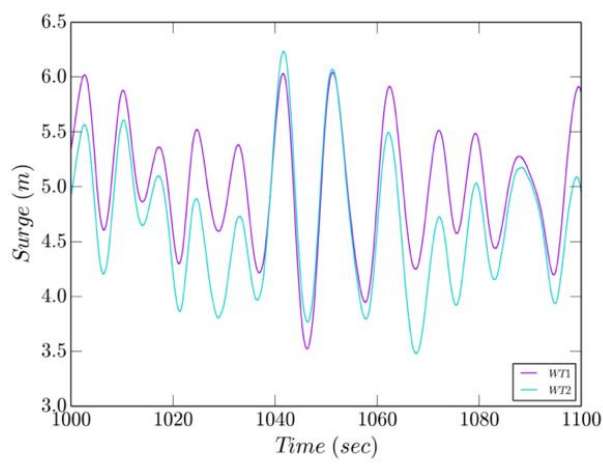

(a)

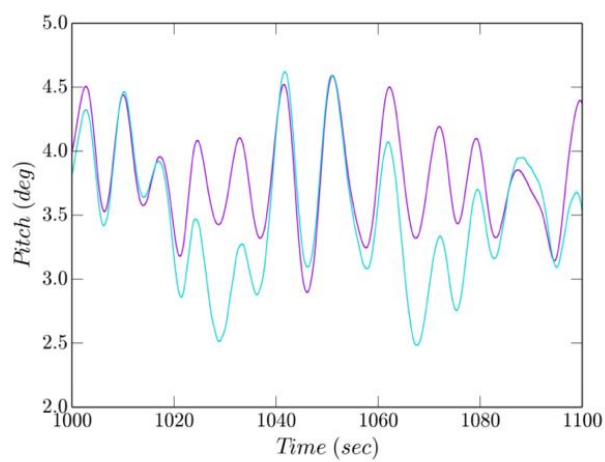

(c)

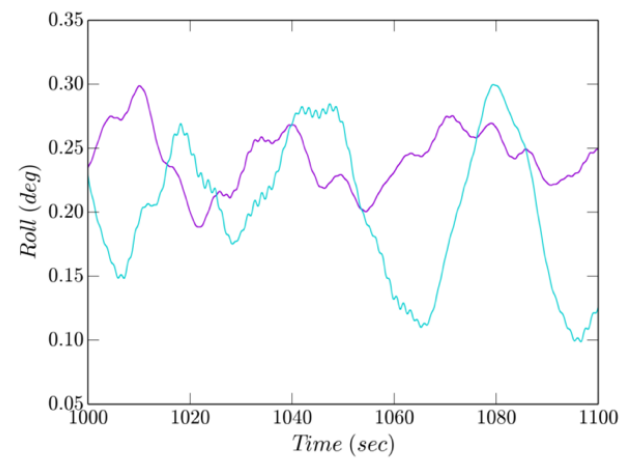

(e)

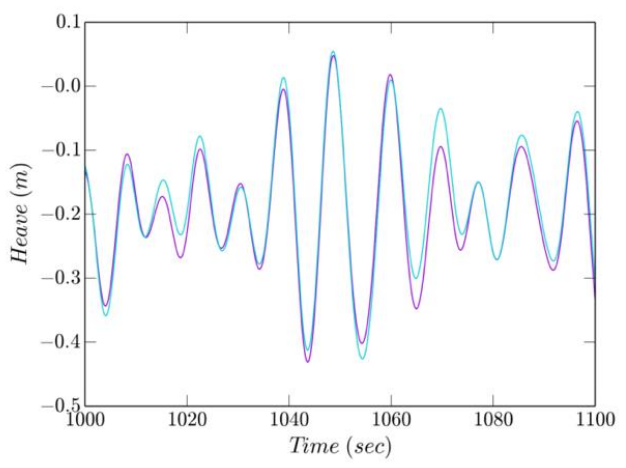

(b)

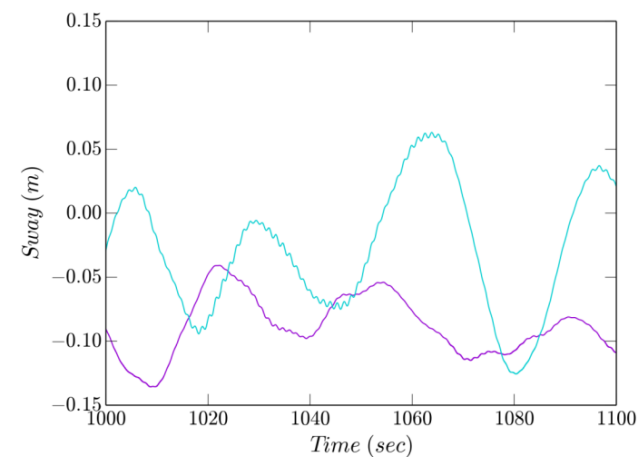

(d)

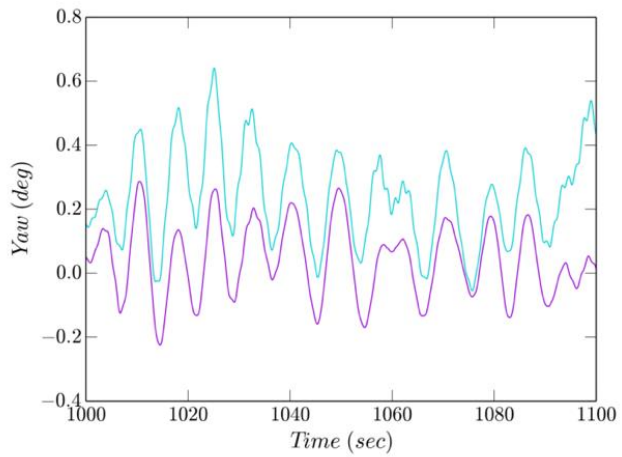

(f)

Figure 12. Floating platform motions of (a) surge, (b) heave, (c) pitch, (d) sway, (e) roll, and (f) yaw from SOWFA.

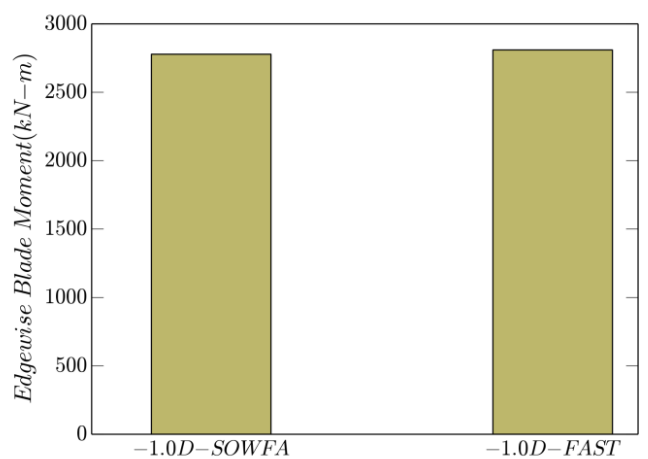

(a)

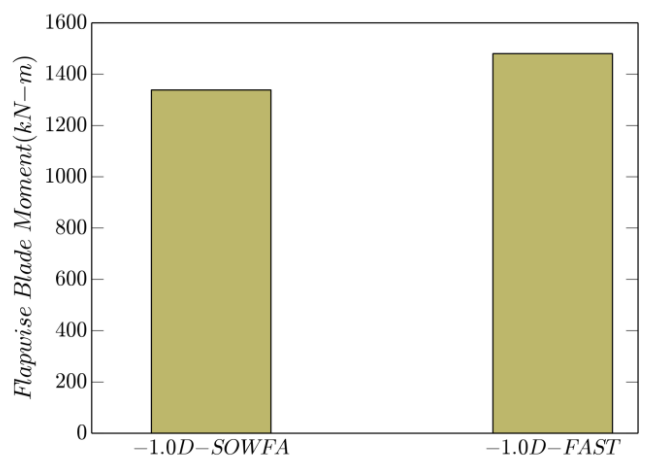

(b)

Figure 13. Damage equivalent loads for (a) edgewise and (b) flapwise blade root moments. 
The influence of the blade rotation interaction with the atmospheric boundary layer is shown in the spectral density plots, denoted as " $1 \mathrm{P}^{\prime}$, " $2 \mathrm{P}$ ", " $3 \mathrm{P}$ ", and " $4 \mathrm{P}$ " (Figures 14 and 15). The large peaks were produced from the individual blades interacting with the turbulent flow, which contributed to exciting the modes at the blade rotational frequencies. However, in the case of the edgewise blade root moment, the "1P" peak was more pronounced compared to other peaks as the gravity was the dominant load.

The sharp peaks (i.e., second peaks) in the platform response (Figure 15) appear at the "3P" frequency, which reflects the collective motions acting on the platform from the three blades. The first spectral peaks in the platform motions were related to the natural frequencies of the platform combined with the turbine. However, the peaks were relatively "smeared", which could be due to the structure's flexibility, which damps the excitations at the natural frequencies, combined with the lack of inputs from the turbulent wind that contained large-scale low-frequency content, as the turbulent inflow wind had limited time series data.

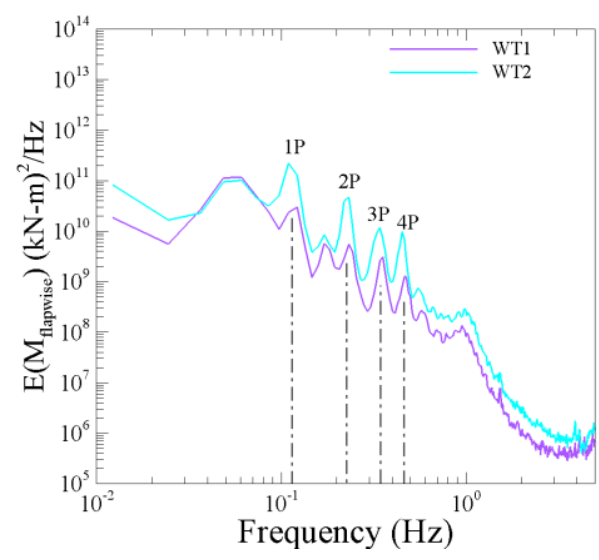

(a)

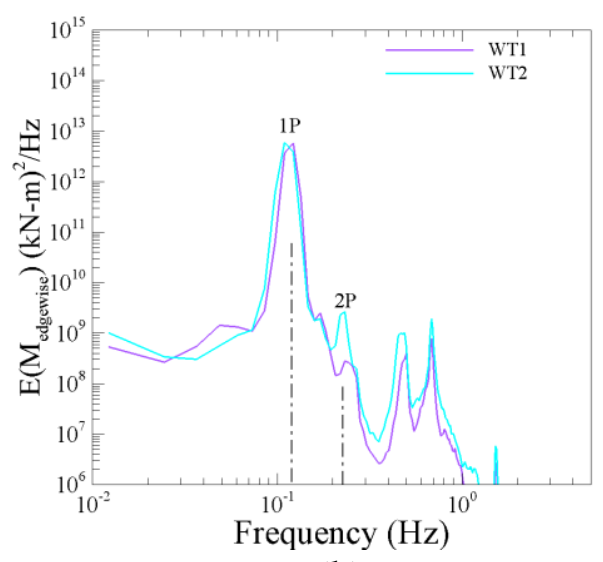

(b)

Figure 14. Spectra of (a) flapwise and (b) edgewise blade root moments from SOWFA.

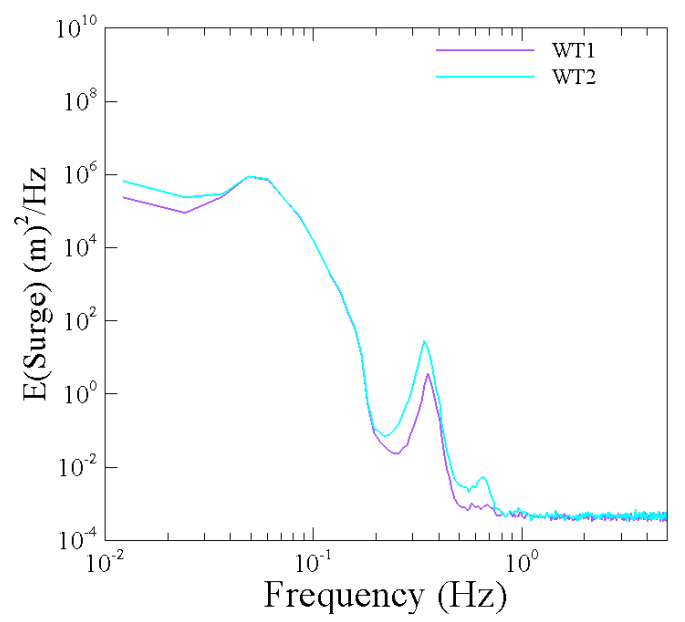

(a)

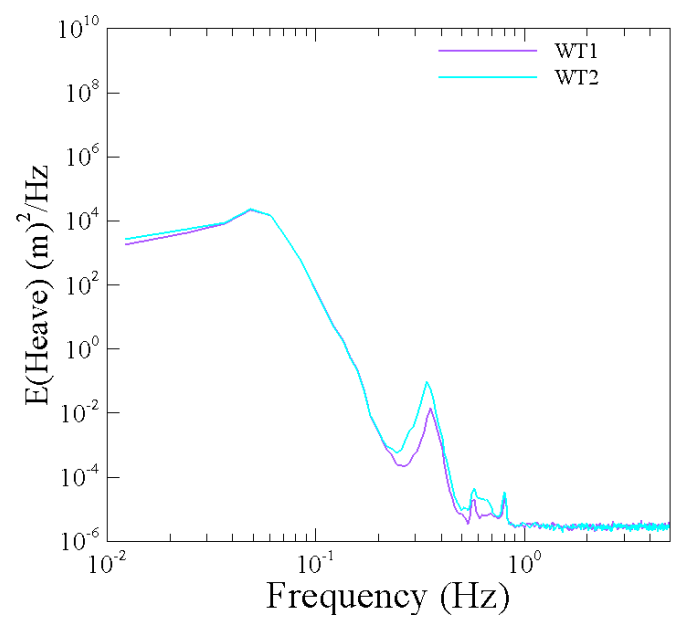

(b)

Figure 15. Cont. 


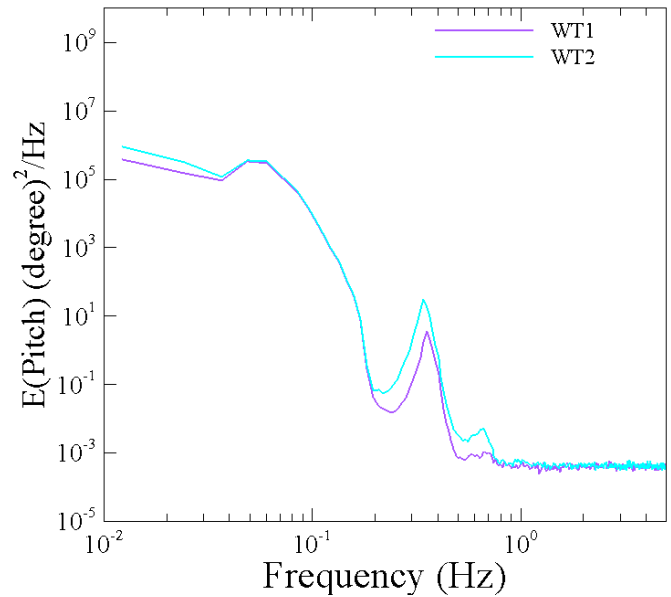

(c)

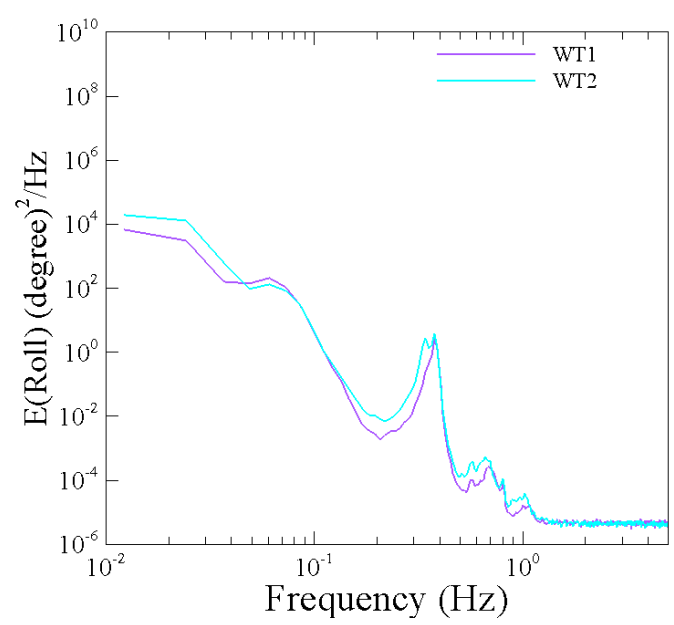

(e)

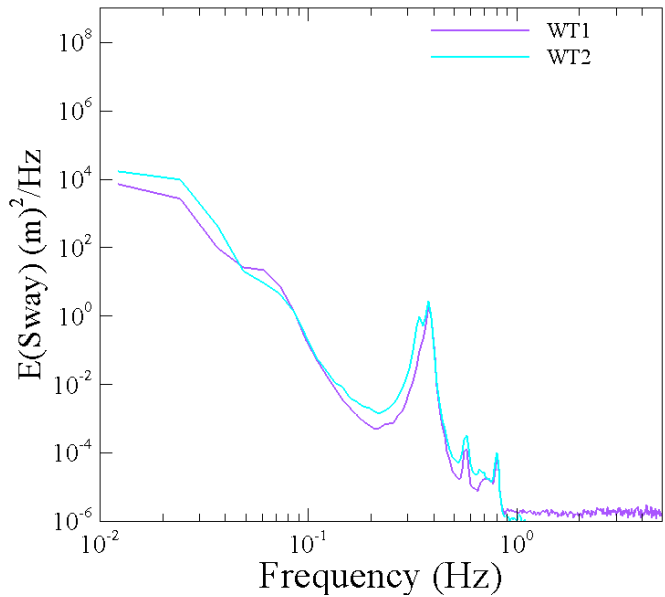

(d)

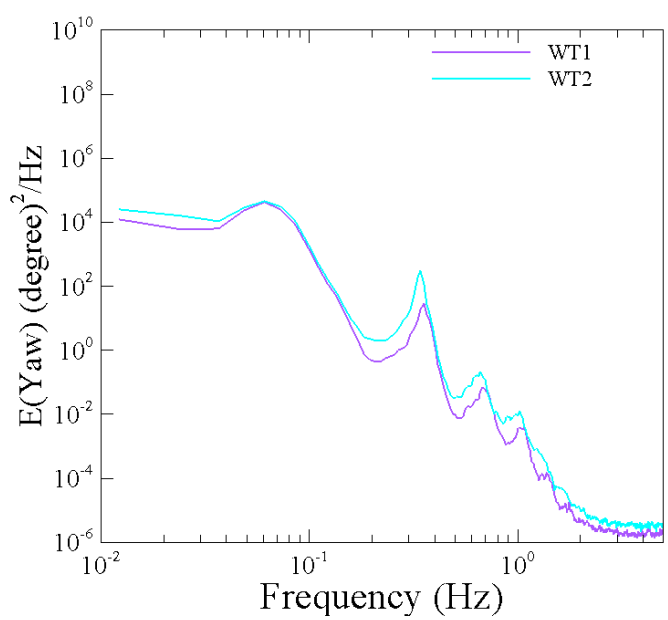

(f)

Figure 15. Spectra of platform motions of (a) surge, (b) heave, (c) pitch, (d) sway, (e) roll, and (f) yaw from SOWFA.

The blade root moments for the edgewise and the flapwise blade root moments represented for a single blade azimuth space are shown in Figure 16. The edgewise moments were nearly identical results as gravity is the dominant force acting on the blades in the edgewise direction for both WT1 and WT2. Note that the rotor revolution per minute (rpm) for WT1 and WT2 were similar (WT1: $14.2 \mathrm{rpm}$; WT2: $13.8 \mathrm{rpm}$ ) as the partial wake on WT2 had a small influence on reducing the rotor speed. The flapwise moments for WT1 and WT2 showed peaks that occurred at different angular positions due to the blade passage through atmospheric turbulent structures which were modified by WT1 in the WT2 case. The peaks reflect the blade moving out of the low-speed structure into the higher flow region, which rapidly increased the moment exerted on the blade. 


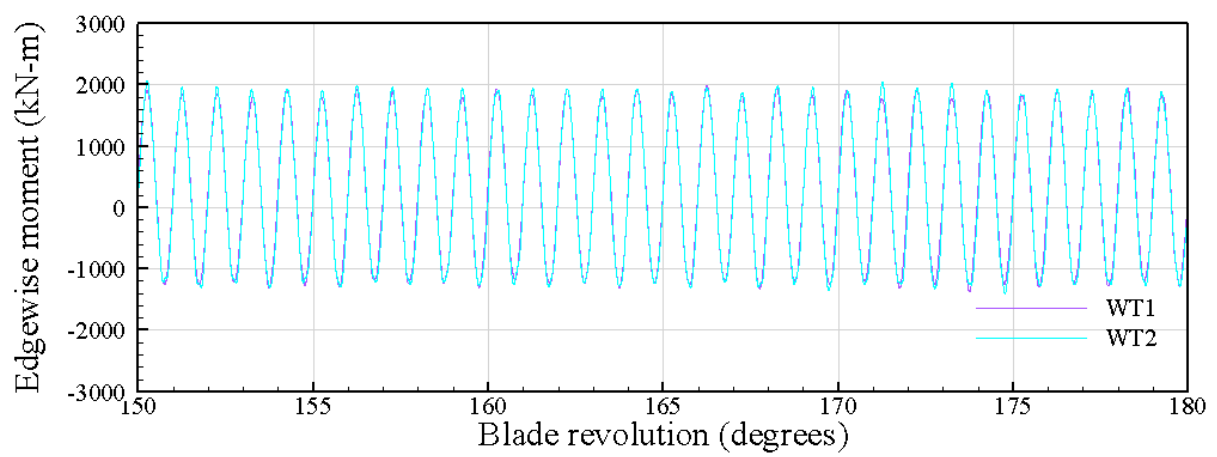

(a)

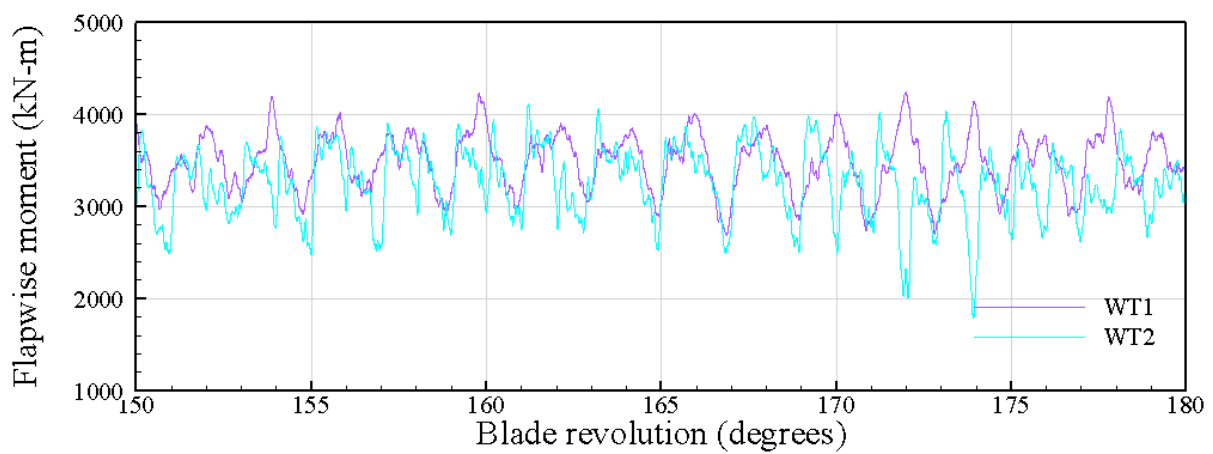

(b)

Figure 16. (a) Edgewise and (b) flapwise blade root moment from SOWFA.

\section{Conclusions}

A large-eddy simulation of an atmospheric boundary layer with two 3 MW turbines on a floating spar platform (Hywind-II) was studied to investigate the impact of a wake generated from the upstream turbine (WT1) on the downstream turbine (WT2). The average hub-height wind speed was $9 \mathrm{~m} / \mathrm{s}$ with the turbulence intensity of $3.7 \%$. By extracting the turbine wake flow field at 7D downstream from LES with a single turbine, the effect of the lateral position of WT2 on the dynamic response was investigated with the aero-elastic tool, FAST. The WT1 wake imparts aerodynamic load on WT2 thereby resulting in the floating platform's motion. Depending on the lateral position of WT2, the upstream wake can impart cyclic loads which increase fatigue on the critical components of the turbine. The damage equivalent load on the blade and the tower was higher for the offset turbine positions on the left side from the centerline. In particular, for the turbine position at $-1 \mathrm{D}$, the damage equivalent load for the flapwise blade root moment increased by $45 \%$ compared to WT1, potentially reducing WT2's service life time. This was attributed to the partial impingement of the upstream wake. On the other hand, the fatigue load on WT2 placed on the right side (0.5D, 1D and 1.5D) of the case with a fully impinged wake position yielded lower fluctuating stress due to the non-symmetric wake shape, which was possibly attributed to the vertical shear of the wind profile and the Coriolis forces that caused direction change with height.

Based on identifying the case producing the highest damage equivalent load, a two-way coupled LES was performed consisting of two turbines with an offset of -1D lateral position. It was found that reasonable agreement was achieved with the previous corresponding one-way coupled FAST simulation, which gave higher confidence of identifying the case with the highest DEL using FAST and SOWFA generated inflows. The partial wake impingement on WT2 significantly increased the fatigue damage as the rotor traversed through a wider range of local wind speeds. The energy spectra at the blade rotational frequencies (i.e., $1 \mathrm{P}, 2 \mathrm{P}, 3 \mathrm{P}$, and $4 \mathrm{P}$ ) for the flapwise blade root moment were an 
order of magnitude higher for WT2. Consistent results were found for the floating platform's surge, pitch and yaw energy spectra for WT2. In general, the downstream turbines were exposed to a higher cyclic fatigue load range, contributing to increased fatigue damage. The partial wake impingement had a significant impact on the downstream turbine, even at a 7D separation distance.

Author Contributions: Conceptualization, F.G.N., S.L., and S.S.; Methodology, S.L., P.M., B.S., F.D., S.S., and J.J.; Software, S.L., B.S., M.C, and S.S.; Validation, S.L., M.C.; Formal Analysis, S.L, P.M., F.D.; Investigation, S.L.; Resources, S.S., P.M., and F.G.N.; Data Curation, S.L.; Writing-Original Draft Preparation, S.L.; Writing-Review \& Editing, S.L.; Visualization, S.L.; Supervision, S.L.; Project Administration, S.S. and E.B.; Funding Acquisition, S.S. and E.B.

Funding: This research was funded through the U.S. Department of Energy Offshore Wind Advanced Technology Demonstration Project.

Acknowledgments: Authors acknowledge the National Renewable Energy Laboratory and University of Bergen's High Performance Computing Center for providing the computational resource to perform the LES study.

Conflicts of Interest: The authors declare no conflict of interest.

\section{References}

1. Hywind. Available online: https://www.statoil.com/en/what-we-do/hywind-where-the-wind-takes-us. html\#why-hywind (accessed on 19 July 2018).

2. Jonkman, J.M.; Buhl, M.L., Jr. FAST Users Guide; Technical Report for National Renewable Energy Laboratory; National Renewable Energy Laboratory: Golden, CO, USA, 2005.

3. Churchfield, M.J.; Lee, S.; National Renewable Energy Laboratory. Simulator for Wind Farm Applications. Available online: http:/ / wind.nrel.gov/designcodes/simulators/sowfa/ (accessed on 19 July 2018).

4. Sorensen, J.N.; Myken, A. Unsteady Actuator Disc Model for Horizontal Axis Wind Turbines. J. Wind Eng. Ind. Aerodyn. 1992, 39, 139-149. [CrossRef]

5. Sorensen, J.N.; Shen, W.Z. Numerical Modeling of Wind Turbine Wakes. J. Fluids Eng. 2002, 124, $393-399$. [CrossRef]

6. Stevens, R.J.A.M.; Martínez-Tossas, L.A.; Meneveau, C. Comparison of Wind Farm Large Eddy Simulations using Actuator Disk and Actuator Line Models with Wind Tunnel Experiments. Renew. Energy 2018, 116, 470-478. [CrossRef]

7. Calderer, A.; Guo, X.; Shen, L.; Sotiropoulos, F. Fluid-structure Interaction Simulation of Floating Structures Interacting with Complex, Large-scale Ocean Waves and Atmospheric Turbulence with Application to Floating Offshore Wind Turbines. J. Comput. Phys. 2018, 355, 144-175. [CrossRef]

8. Baba-Ahmadi, M.H.; Dong, P. Validation of the Actuator Line Method for Simulating Flow Through a Horizontal Axis Tidal Stream Turbine by Comparison with Measurements. Renew. Energy 2017, 113, 420-427. [CrossRef]

9. Martínez-Tossas, L.A.; Churchfield, M.J.; Meneveau, C. A Highly Resolved Large-Eddy Simulation of a Wind Turbine using an Actuator Line Model with Optimal Body Force Projection. J. Phys. Conf. Ser. 2016, 753. [CrossRef]

10. Churchfield, M.J.; Lee, S.; Michalakes, J.; Moriarty, P.J. A numerical Study of the Effects of Atmospheric and Wake Turbulence on Wind Turbine Dynamics. J. Turbul. 2012, 13, 14, 1-32. [CrossRef]

11. Jonkman, J.M.; Matha, D. Dynamics of Offshore Floating Wind Turbines-Analysis of Three Concepts. Wind Energy 2011, 14, 557-569. [CrossRef]

12. Christiansen, S.; Bak, T.; Knudsen, T. Damping Wind and Wave Loads on a Floating Wind Turbine. Energies 2013, 6, 4097-4116. [CrossRef]

13. Jonkman, B.J. TurbSim User's Guide; Technical Report for National Renewable Energy Laboratory; National Renewable Energy Laboratory: Golden, CO, USA, 2009.

14. WAMIT. Available online: https:/ / www.wamit.com/ (accessed on 19 July 2018).

15. Sebastian, T.; Lackner, M. Analysis of the Induction and Wake Evolution of an Offshore Floating Wind Turbine. Energies 2012, 5, 968-1000. [CrossRef]

16. Jeon, M.; Lee, S.; Lee, S. Unsteady Aerodynamics of Offshore Floating Wind Turbines in Platform Pitching Motion Using Vortex Lattice Method. Renew. Energy 2014, 65, 207-212. [CrossRef] 
17. Lee, S.; Churchfield, M.J.; Moriarty, P.J.; Jonkman, J.; Michalakes, J. A Numerical Study of Atmospheric and Wake Turbulence Impacts on Wind Turbine Fatigue Loadings. J. Sol. Energy Eng. 2013, 135. [CrossRef]

18. Fleming, P.A.; Gebraad, P.M.O.; Lee, S.; Wingerden, J.W.V.; Johnson, K.; Churchfield, M.; Michalakes, J.; Spalart, P.; Moriarty, P. Evaluating Techniques for Redirecting Turbine Wakes using SOWFA. Renew. Energy 2014, 70, 211-218. [CrossRef]

19. Downing, S.D.; Socie, D.F. Simple Rainflow Counting Algorithms. Int. J. Fatigue 1982, 4, 31-40. [CrossRef]

20. Sutherland, H.J. On the Fatigue Analysis of Wind Turbines; Technical Report for U.S. Department of Energy; U.S. Department of Energy: Washington, DC, USA, 1999.

2018 by the authors. Licensee MDPI, Basel, Switzerland. This article is an open access article distributed under the terms and conditions of the Creative Commons Attribution (CC BY) license (http:/ / creativecommons.org/licenses/by/4.0/). 